Volume 9, No.4, July - August 2020

International Journal of Advanced Trends in Computer Science and Engineering

Available Online at http://www.warse.org/IJATCSE/static/pdf/file/ijatcse286942020.pdf

https://doi.org/10.30534/ijatcse/2020/286942020

\title{
Fuzzy based Decision Support Model on Determining the Most Eligible Location of National Multi-Sport Event
}

\author{
Ditdit Nugeraha Utama ${ }^{1}$, Isnaini Monita Safitri ${ }^{2}$, Nada Rahmi Safira ${ }^{2}$, Ahmad Labib Alfaleh ${ }^{2}$, \\ Fikri Rama Singgih ${ }^{2}$ \\ ${ }^{1}$ Computer Science Department, BINUS Graduate Program - Master of Computer Science, Bina Nusantara \\ University, Jakarta, Indonesia 11480 \\ ${ }^{2}$ Information System, Universitas Islam Negeri Syarif Hidayatullah, Jakarta, Indonesia
}

\begin{abstract}
National or international multi-sport event is a regular event held by one country. Specifically, in arranging the national multi-sport event, or called as national sport week (NSW) in Indonesia, is a challenging case. It should be practically convened in different province in every four years. Indonesia has thirty-four provinces with unique characteristic and culture and Indonesia national sport committee (INSC) should make a decision which province is proper to organize such an event. The study was scientifically performed to develop a decision support model (DSM) based on fuzzy logic and linear regression methods in determining the most proper location to hold NSW. By taking eight parameters into account, the constructed model was able to suggest the best location for conducting NSW for next event.
\end{abstract}

Key words: multi-sport event, national sport week, decision support model, fuzzy logic, linear regression.

\section{INTRODUCTION}

Sport is an activity that has many benefits for our body. There are various kinds of sports that well known, such as soccer, swimming, badminton, and so on. Organizing a multi-sport event has become commonplace in social life to show achievement in every existing sport. Usually these multi-sport events contain various competitions and sports competitions for each branch. In organizing a multi-sport event, it can have certain effects and impacts on the host region, so that it does not only hold sport competitions and competitions, but also introduces and advances the area.

Therefore, it is not surprising that many regions or countries compete to host such a multi-sport event, especially multi-sport event that has been scheduled regularly at the national level, as well as at the international level. In Indonesia there is a national-level multi-sport event which is participated by all provinces in Indonesia and is held every four years, the event is the national multi-sport event or called as national sport week (NSW). The NSW was first held by the Indonesian national sport committee (INSC) in 1948 in the city of Solo, Central Java and so far it has been held 19 times in various provinces in Indonesia. The purpose of the NSW is that sports achievements in Indonesia have national standards so that they can take part in international multi-sport events, such as the Olympics and the Asian Games. So far, the determination of locations for the holding of NSW uses random voting and throwing.

Basically, humans naturally go through three major stages in the process of making a decision, even for decisions that are sudden even though, the three sequential stages are: intelligence, design, and choice then proceed with the action to see whether the results are good or not [1]. So we have an idea to perform a study in determining its location thru developing a decision support model (DSM) using the fuzzy logic and linear regression methods. In our study, all provincial locations in Indonesia were used as samples to obtain a total of 34 samples. Each province must have different conditions and values depending on the sample data. So we determined the parameters that can be used as a standard consideration of the feasibility of the province as the host in the implementation of NSW. Then we sorted these parameters according to the importance of priority in making a decision, namely the amount of the budget, the number of sports arenas, sports arena ratings, crime rates, number of security forces, number of three or more starred hotels, number of police stations, and the number of tourism.

We hope this research is able to help the organizers of the NSW as a supporter of his decision. That way, the selection of provincial locations can be adjusted to the different vision and mission of each NSW organization depending on the wishes of the committee. For example, the NSW committee wants to advance a province even though the amount of the budget and the number of sport arenas is small, but being hosted by the NSW will have an impact on the progress of the province, because hosting a NSW requires a lot of preparation and maturity, so that it can motivate the area to develop. Our 
research only focuses on determining the location according to the eight parameters that have been mentioned and according to the data we have obtained, beyond that scope we have not discussed it in this research assignment report. So that the location of the host of NSW hosting is not documented or the stages are invalid, so with this research that provides decision support, it is expected that the location selection will be clearly visible and each province will have their turn.

\section{LITERATURE OVERVIEW}

\subsection{Decision Support Model (DSM)}

According to [1][2], a DSM is an interactive model that provides information, modeling, and manipulation of data that is used to help decision making in semi-structured and unstructured situations where no one knows exactly how decisions should be made. In principle, when a model (including calculations, parameters involved, determining the amount of its values, and interactions in it, or whatever it is) supports decision makers in making decisions (which logical, rational, and structured, right) on complex problems (or semi-complex) that have so many parameters that must be considered, whether it is computer based or not [1].

\subsection{Fuzzy Logic}

The fuzzy system was first invented by Prof. Lotfi A. Zadeh in the mid-1960s at the University of California, Berkeley [3]. Fuzzy logic or biased logic is a method that adopts human judgment on a truth, which is expressed in a continuous function from 0 to 1 . In contrast to classical logic which states everything in binary terms ( 0 or 1 , yes or no) [4]. Thus, parameter values are not understood as absolute precise values, but parameter values can also be understood as a bias value. Fuzzy logic algorithm can be seen in a precise value (exact, certain; or called crisp input), which we must then convert into a fuzzy value (the value of bias with the fuzzy logic rules illustrated), through the fuzzification process. Then, via the de-fuzzification process, we is again going to get a fixed value, or we call crisp output [5].

Conceptually, fuzzy logic has three process: fuzzification, inference (rule base), and de-fuzzification. The fuzzification process changes inputs with crisp truth value into fuzzy input. To do the fuzzification process, several things required: linguistic variable representation and membership function. The membership function is a representation of language variables mapped to the degree of the truth (DoT) or degree of certainty (DoC), where DoT has a value between 0 and 1 . One of the key representations of membership functions, a language variable should overlap with other language variables. Next, we are able to determine the shape of the language variable. There are various forms that are commonly used, among which are triangular functions, trapezoidal functions, logistic functions, and Gaussian functions. The two commonly used shapes are triangle and trapezoid [1].

In inference (rule based) process, reasoning using fuzzy input and fuzzy rules determined, so that it produces fuzzy output. In syntax, a fuzzy rule is written as IF antecedent THEN consequent. And then, de-fuzzification process change fuzzy output to crisp output value based on a predetermined membership function.

\section{RESEARCH METHODOLOGY}

\subsection{Population, Samples, and Sampling Techniques}

As discussed earlier, we took the topic of location decision making for the implementation of NSW in Indonesia. The population which is defined as our parameter is sorted by priority according to our opinion or rule-based, namely: the amount of the budget in each province, the number of sport arenas in each province, sports arena rating in each province, the level of crime in each province, the number of security forces in each province, the number of three or more starred hotels in each province, the number of police stations in each province, and the number of tourism in each province.

The reason why we take that population as a parameter in this case. The first parameter we prioritized is the amount of the provincial budget. The amount of budget in each province is the most important parameter in the selection of NSW host provinces. Because the greater the budget in a province, the more a portion of the budget is allocated for the implementation of NSW. The more budget allocated to NSW, the potential for running NSW in the area in accordance with stakeholder expectations will be even higher. As the host, it requires a lot of preparation for the holding of NSW later, where the preparation would require funds sourced from the Regional Revenue and Expenditure Budget (RRED), the State Revenue and Expenditure Budget (SRED), and NSW sponsorship funds [6]. SNSW funding is also needed to maximize the budget and also become a major issue regarding sports marketing in the management of an event [7].

The second parameter is the number of sport arenas. As in the paper whose type of research resembles that of our research [8], it is mentioned that the sports arena is a very important consideration in organizing an Olympic sports event. Because NSW held a competition of 44 sports, a large number of sports arenas were needed to facilitate the 44 sports. In addition to facilitating the 44 sports, a large number of sports arenas can also be an alternative if one of the choices of sports arenas in a city within the province cannot be used.

Third, we determined that the arena sports rating is an important parameter after the two parameters above. Why? Because the rating of the sports complex is very influential on several parties. The first party were athletes who competed in NSW. Because the rating itself is seen from several aspects such as the facilities provided by the complex to the athlete, it could also be the condition of the place where one of the sports 
is held, the better the rating of the complex will have the possibility of influencing the athlete's own game. Readiness of facilities and infrastructure in the sports arena is very important ahead of the implementation of NSW or similar events [9]. We concluded the sample data for this sport arena rating parameter based on reviews obtained from Google and Wikipedia.

The safety of the athletes and also the staff participating in the NSW event is an unavoidable priority. Therefore we considered the level of crime in a province to be one of the parameters in our case. As mentioned in the paper whose research resembles ours, security is an important consideration too [8]. We took the province with the lowest crime rate as the best point because the lower the crime rate, the level of the possibility of security threats for all those involved in NSW activities will be low. If the crime rate of a province is high, it will require a large number of officers. With these conditions, to balance the crime rate, we put the number of security personnel into the parameters of our consideration. The implementation of NSW requires a high level of security because the number of participants is not small, many lives are at stake here. Many unexpected events have occurred at previous events, so that a security apparatus is needed to be ready to protect everyone who is at the event [10]. A high level of security can be achieved by several factors, one of which is the number of security forces. The more the number of officers, the higher level of security.

INSC as the organizer of NSW has set lodging standards for athletes participating in NSW. The predetermined standard is that the minimum lodging / hotel that can be chosen as a place for participants to rest is a three-star hotel or more. Therefore we include the number of three or more starred hotels in a province. If hotels with three or more stars in a province are counted, there will be many alternative choices to determine which the best place to rest for NSW athletes is.

A large number of officers will also require a large number of offices / guard posts. The office / guard post is also useful when in the conduct of NSW a crime is committed, then the closest guard office / post is needed at the time of this incident. How can crime problems be dealt with quickly if there is no office / guard post that can receive reports of crime in the administration of NSW? Therefore, we include the number of guarding offices / posts in each province into consideration the parameters of our case. To reduce the risk of delays in responding to unforeseen events later, it is necessary to have office locations / guard posts closest to the event organizing area [11], which in our opinion affects the number of offices / guard posts in a province.

Implementation of NSW will attract viewers, both from the organizing province and from outside the province. Our intention is to include the parameter of the amount of tourism available, so that viewers who come not only see the implementation of NSW, but can also enjoy the tourism available in the province. If there are many spectators who travel, the income for the province will also increase, so the value of the province in the eyes of people outside the province will be good. If revenues increase, the province can potentially advance regions that are still remote in their province. A region is trying to hold a big event such as the Olympics because there are many benefits related to increasing tourism and wealth flowing into the area [12], so in our opinion with the addition of these parameters the chosen province has its own advantages and can also be of value add to the country.

\subsection{Research Procedure}

We conducted this research from the stages of determining the research topic to applying the results with the dashboard as the user interface. Figure $\mathbf{1}$ is the procedures for the stages of our research.

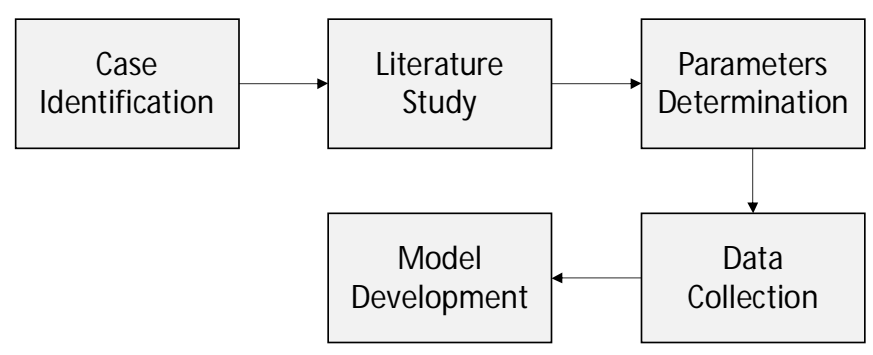

Figure 1: Research Stages

The purpose of the Figure 1 for more details mentioned here. The first step we took is to look for ideas as our research theme. After the theme has been identified, then we looked for scientific manuscripts related to the theme to determine what parameters will be operated. Based on the manuscripts we have obtained, we concluded eight parameters mentioned earlier. After the parameters have been determined, we determined the sample taken for this study that was all provinces in Indonesia because the theme we took discusses national standard multi-sport events. Then we look for data related to predefined parameters,

Then, the model construction was done. We made the membership function and linguistic variables as the calculation scale. After that we started to calculate the value of bias (fuzzy) using the linear regression formula data and membership function that has been set. Then we make a rule base as a reference rule in determining the results of consideration so that we get 6,561 rule bases.

\subsection{Data Collecting}

In collecting data, we used secondary data sources, which are data obtained by researchers from existing sources. With data collection techniques and information needed / obtained through other written records relating to the problem under study. This data research was carried out from literature 
study, which is by collecting data from national and international scientific journals, e-books, theses, scientific papers, and books. We operated this technique to trace various theories, examine and apply them to research implementation and analysis. The search and study of theoretical foundations by studying books, magazines, newspapers, document reports and other literature relating to research. We used this literature study technique to find and complete the necessary theoretical foundations.

In taking and collecting data for each sample that has been determined, we do it in the following ways. We got sample data for the parameters of each province's budget from the Directorate General of Regional Financial Development files that can be accessed openly through the Central Statistics Agency website. We got sample data for the parameters of the number of sports arenas in each province from the website owned by each province. We concluded the sample data for this sport arena rating parameter based on reviews obtained from Google and Wikipedia.

Furthermore, we obtained sample data for this province's crime rate parameters from the BPS e-book on Criminal Statistics. We got sample data for the parameter number of officers in each province based on PER (Police Employee Rate) calculations obtained from Yahoo's search website. We obtained sample data for parameters for the number of three or more starred hotels in this province from data in the Traveloka and Trivago applications. We obtained sample data for the parameter number of offices / guard posts in each of these provinces from an article posted on one of the website pages. We got sample data for the parameter of the number of tourism places in each of these provinces from the data in the Local Tourism application.

\section{CONSTRUCTED MODEL \\ 4.1. Data Analyzing}

Eight parameters were successfully selected. They are budget amount, sport arena number, sport arena rating, crime rate, apparatus number, three or more stars hotel number, police station number, and tourist number. In fuzzy logic conception, they are represented via linguistic variable and overlap range (please see Table 1) that depict each province's condition in Indonesia. And respectively, all triangular membership functions are configured by Figures 2-9.

Table 1: Selected Parameters with Their Linguistic Variables and Range

\begin{tabular}{|c|l|l|l|l|}
\hline No & Parameter & \multicolumn{1}{|c|}{$\begin{array}{c}\text { Linguistic } \\
\text { Variable }\end{array}$} & \multicolumn{1}{c|}{ Range } & Unit \\
\hline 1. & $\begin{array}{l}\text { Budget } \\
\text { Amount }\end{array}$ & Few (F) & $\leq 35.20$ & Billion rupiah \\
\hline & & Average (A) & $1.40-69.00$ & Billion rupiah \\
\hline & & Many (M) & $\geq 35.20$ & Billion rupiah \\
\hline 2. & $\begin{array}{l}\text { Sport Arena } \\
\text { Number }\end{array}$ & Few (F) & $\leq 26$ & Units \\
\hline
\end{tabular}

\begin{tabular}{|c|l|l|l|l|}
\hline & & Average (A) & $7-45$ & Units \\
\hline & & Many (M) & $\geq 26$ & Units \\
\hline 3. & $\begin{array}{l}\text { Sport Arena } \\
\text { Rating }\end{array}$ & Bad (B) & $\leq 3$ & Rating point \\
\hline & & $\begin{array}{l}\text { Moderate } \\
\text { (Mo) }\end{array}$ & $1-5$ & Rating point \\
\hline 4. & Crime Rate & Loo (G) & $\geq 3$ & Rating point \\
\hline & & Medium (Me) & $48-328$ & Cases \\
\hline & & High (H) & $\geq 188$ & Cases \\
\hline 5. & $\begin{array}{l}\text { Apparatus } \\
\text { number }\end{array}$ & Low (L) & $\leq 15,369$ & Apparatus \\
\hline & & Medium (Me) & $459-30,279$ & Apparatus \\
\hline 6. & $\begin{array}{l}3 \text { or More } \\
\text { Star Hotel } \\
\text { Number }\end{array}$ & Low (L) & $\leq 831$ & Apparatus \\
\hline & & Medium (Me) & $2-2,261$ & Units \\
\hline & & High (H) & $\geq 831$ & Units \\
\hline 7. & $\begin{array}{l}\text { Police } \\
\text { Station } \\
\text { Number }\end{array}$ & Low (L) & $\leq 22$ & Units \\
\hline & & Medium (M) & $4-40$ & Units \\
\hline & & High (H) & $\geq 22$ & Units \\
\hline 8. & $\begin{array}{l}\text { Tourist } \\
\text { Number }\end{array}$ & Low (L) & $\leq 316$ & Thousand/month \\
\hline & & Medium (Me) & $24-609$ & Thousand/month \\
\hline & & High (H) & $\geq 316$ & Thousand/month \\
\hline
\end{tabular}

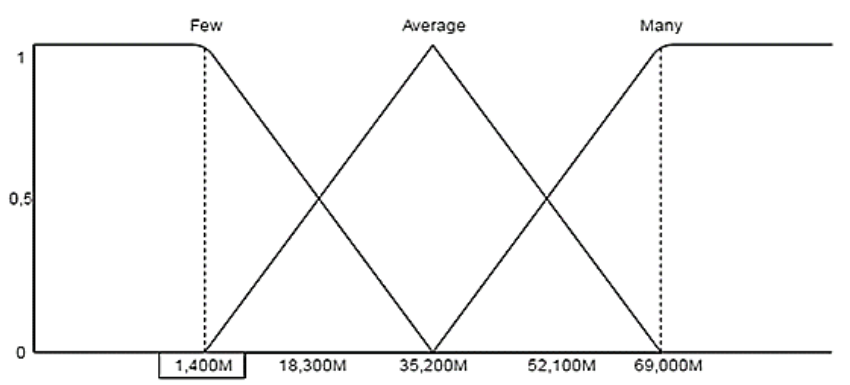

Figure 2: Triangular Membership Function for Budget Amount

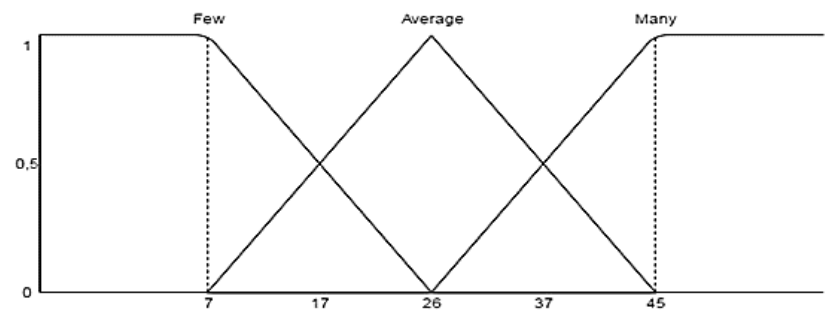

Figure 3: Triangular Membership Function for Sport Arena Number

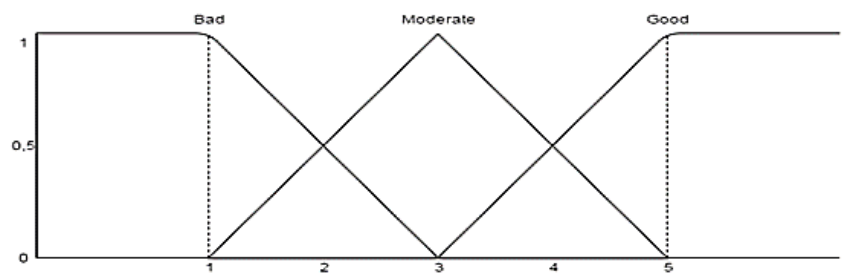

Figure 4: Triangular Membership Function for Sport Arena Rating 


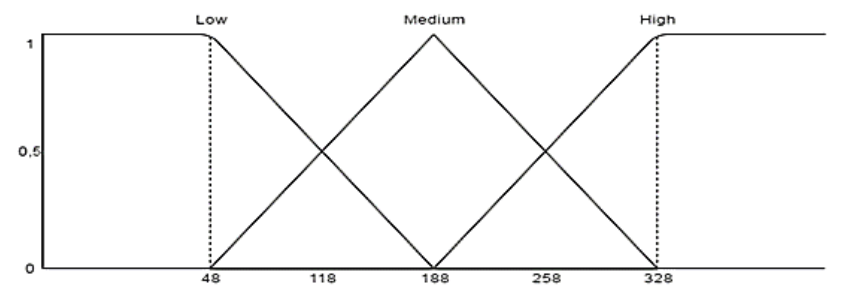

Figure 5: Triangular Membership Function for Crime rate

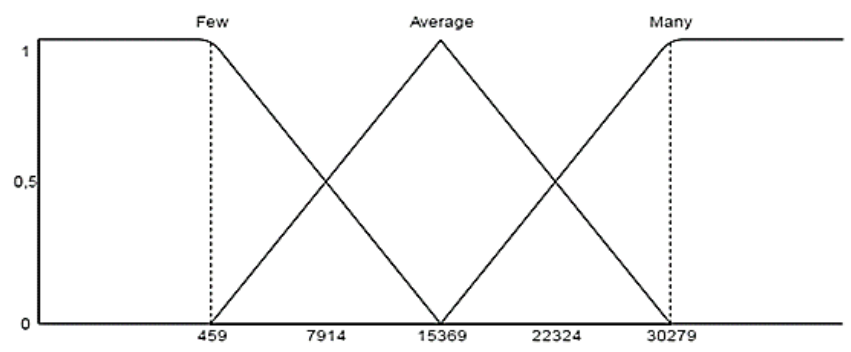

Figure 6: Triangular Membership Function for Apparatus Number

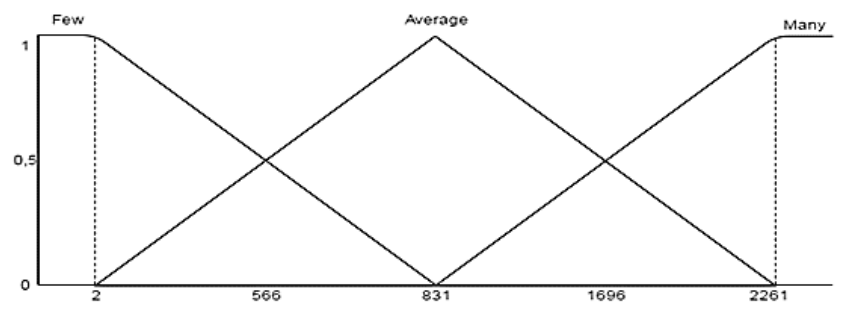

Figure 7: Triangular Membership Function for 3 or more Star Hotel Number

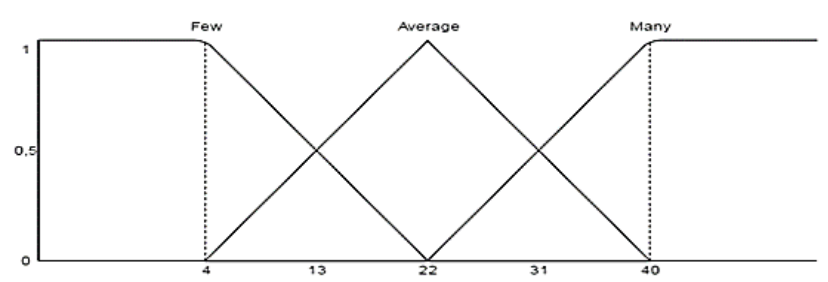

Figure 8: Triangular Membership Function for Police Stations Number

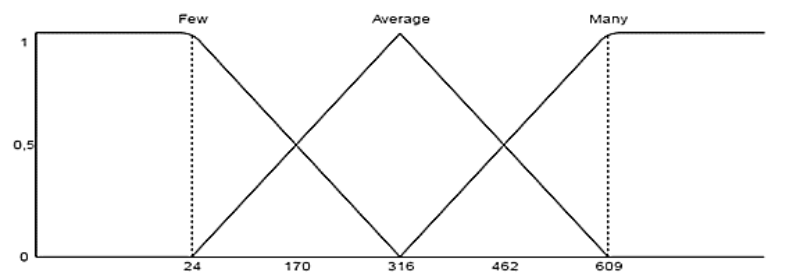

Figure 9: Triangular Membership Function for Tourism Number

\subsection{Calculation Result}

At this stage, the calculation is done to get the value of fuzzy, we functioned a linear representation. In linear representations, mapping the input to the degree of membership is drawn as a straight line. This form is the simplest and a good choice for approaching a concept that is less clear. There are 2 states of fuzzy set which are liner. First, the increase in the set starts at the domain value that has a zero membership degree (0) moves right to the domain value that has a higher membership degree. The linear representation membership function can be defined. Second, it is the opposite of the first. The straight line starts from the value of the domain with the highest degree of membership on the left hand side of one (1), then moves down to the value of the domain that has a lower membership degree to zero (0).

Especially for the fuzzy logic method, simple mathematical logic applies. When two conditions are connected with AND logic ( $\Lambda$, called conjunction), then the condition with the smallest or minimum value becomes the choice. Whereas when two conditions are connected with the logic OR (V, called disjunction), then the condition with the largest or maximum value chosen [1]. To determine the results, we compare the descending and ascending bias values of each parameter by selecting the largest value using simple mathematical disjunction / OR, so that the verbal linguistic is adjusted to the membership function of each parameter as seen from the lines on the graph. membership down or up. The following is the result of calculating the value of bias (fuzzy) using the linear representation rules that have been determined in accordance with the membership function according to [13].

Table 2: Data Example for Each Province's Parameter Fuzzy Number

\begin{tabular}{|l|l|l|l|l|}
\hline No. & \multicolumn{1}{|c|}{ Province } & \multicolumn{1}{|c|}{ BA } & $\ldots$ & \multicolumn{1}{|c|}{ TN } \\
\hline 1. & Aceh & $0.56 \mathrm{~F}$ & $\ldots$ & $0.55 \mathrm{Me}$ \\
\hline 2. & Sumut & $0.75 \mathrm{~F}$ & $\ldots$ & $0.57 \mathrm{Me}$ \\
\hline$\ldots$ & $\ldots$ & $\ldots$ & $\ldots$ & $\ldots$ \\
\hline 33. & West Papua & $0.86 \mathrm{~F}$ & $\ldots$ & $0.92 \mathrm{~L}$ \\
\hline 34. & Papua & $0.68 \mathrm{~F}$ & $\ldots$ & $0.77 \mathrm{~L}$ \\
\hline
\end{tabular}

Table 2 represents example data for each province's parameter fuzzy value. It is talking individually about budget amount (BA), sport arena number (SAN), sport arena rating $(\mathrm{SAR})$, crime rate $(\mathrm{CR})$, apparatus number $(\mathrm{AN})$, three or more stars hotel number (HR), police station number (PSN), and tourist number (TN).

\subsection{Fuzzy Rule Base}

Fuzzy rule base is another element needed to solve a classical problem by using the concept of fuzzy logic intact. Because, in addition to the fuzzification and de-fuzzification processes, to change the value of crisp-fuzzy-crisp, this fuzzy rule base must also exist as a pattern of analysis of the relationship between its parameters. Where some fuzzy components, combined with the basis of these rules [14][15]. We got 6,561 rule bases from parameters and verifiable linguistics, so that the results can be determined in the form of a province feasibility rule that will host NSW (there are two decisions: eligible/E and not eligible/NE). Table 3 shows fuzzy rules 
functioned in the model with 576 rules for $\mathrm{E}$ and 5,985 rules for NE).

Table 3: Fuzzy Rules

\begin{tabular}{|l|l|l|l|l|}
\hline No. & BA & $\ldots$ & TN & Decision \\
\hline 1. & F & $\ldots$ & L & NE \\
\hline 2. & F & $\ldots$ & $\mathrm{Me}$ & NE \\
\hline$\ldots$ & $\ldots$ & $\ldots$ & $\ldots$ & $\ldots$ \\
\hline 6,560 & $\mathrm{M}$ & $\ldots$ & $\mathrm{Me}$ & $\mathrm{NE}$ \\
\hline 6,561 & $\mathrm{M}$ & $\ldots$ & $\mathrm{H}$ & $\mathrm{NE}$ \\
\hline
\end{tabular}

\subsection{DisCUSSION}

After finding the linguistic results of the variables through the calculation of linear representation rules and simple mathematical disjunction logic, we then adjust the results to the rule base we have made.

Table 4: Result of Eligibility Decision

\begin{tabular}{|l|l|l|l|l|l|}
\hline No. & Province & BA & $\ldots$ & TN & Decision \\
\hline 1. & Aceh & F & $\ldots$ & Me & NE \\
\hline 2. & Sumut & F & $\ldots$ & $\mathrm{Me}$ & NE \\
\hline$\ldots$ & $\ldots$ & $\ldots$ & $\ldots$ & $\ldots$ & $\ldots$ \\
\hline 12. & West Java & A & $\ldots$ & Me & E \\
\hline$\ldots$ & $\ldots$ & $\ldots$ & $\ldots$ & $\ldots$ & $\ldots$ \\
\hline 33. & West Papua & F & $\ldots$ & L & NE \\
\hline 34. & Papua & F & $\ldots$ & L & NE \\
\hline
\end{tabular}

Based on 34 samples available, only 1 sample that met the criteria to be Eligible as the host of the National Sports Week was held in the province of West Java / Jawa Barat (see Table 4). Previously, when making a rule base, we discussed the feasibility level for the final results of this study, namely by determining the minimum feasibility of each linguistic outcome of the parameter variables based on the rule base that we made. The minimum eligibility in question is: the sample can be said to be feasible if the parameter value of the minimum or moderate minimum budget amount, the parameter value of the minimum or medium number of sports arenas, the parameter value of the low or moderate minimum crime rate, the parameter value of the number of minimum or moderate security personnel, and the parameter value is the number of third or more star hotels of at least medium or many. Whereas, for the parameters of the sports arena rating, the number of offices / security posts, and the number of tourism we did not make were of minimum eligibility because these parameters had an effect but were not significant in determining the location of the host of the NSW. Due to the results we only get 1 out of 34 samples, so we don't do crisp output at the de-fuzzification stage. The following is a table of the results of eligibility along with the location of the rule base in each sample.
In determining the NSW implementation area, there are eight parameters that become the reference, namely; provincial budget, number of sports arenas, sports arena rating, provincial crime rates, number of security forces, number of hotels with a minimum of three stars, number of tourist attractions, and number of police stations. Based on the dashboard above, at the bottom there are data calculation results per parameter with the calculation object is the province of West Java (Jawa Barat). While at the top right of the picture, there is a map of the calculation object, namely the map of West Java province. At the bottom, there is a dialog box showing the final results of the calculation in which West Java was selected as a suitable area to carry out the next NSW with the results; 0.74 in the parameter budget amount; 0.68 on the parameter number of sports arena; 1.00 on the sport arena rating parameter; 0.82 on the crime rate parameter; 1.00 in the parameter number of security forces; 0.90 in the parameter number of 3 or more starred hotels; 0.72 on the parameter number of offices / guard posts; and 0.71 on the parameter of the amount of tourism which is blue, because if the province is not feasible it will be red.

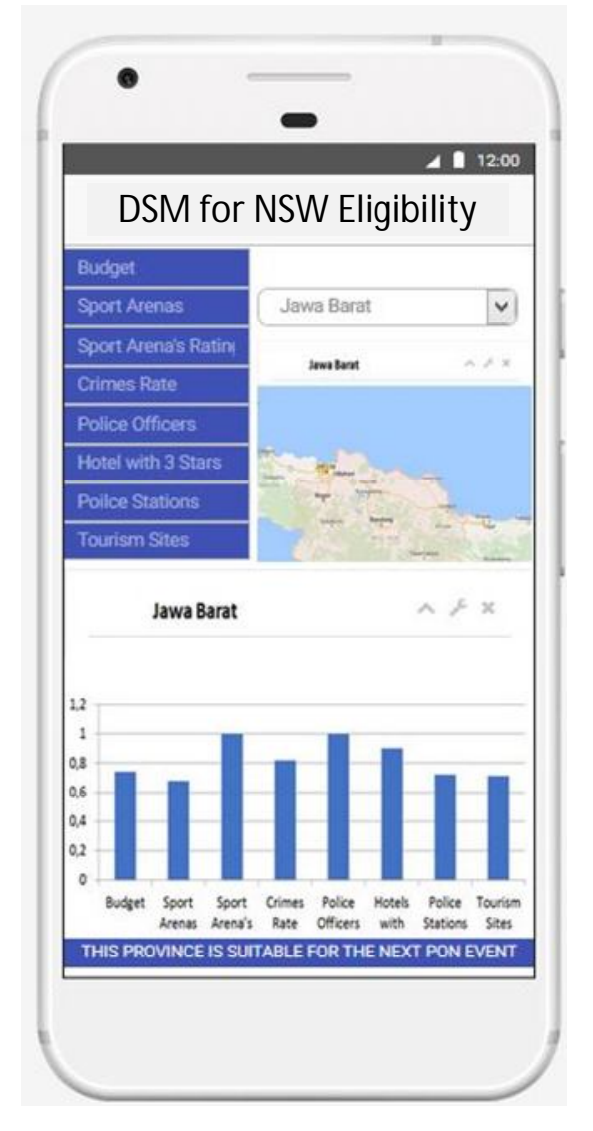

Figure 10: Dashboard for Constructed Model

\section{CONCLUSION AND FURTHER WORKS}

The conclusion that can be drawn from the research presented above is that we used the fuzzy logic method to get the results of supporting the feasibility of the location as the host of the 
NSW. Through the stages we carried out from determining the research topic to getting the final result in the form of 1 sample from 34 existing samples. The results are obtained through eight reference parameters in sequence according to their priority with each fuzzy value calculated based on linear representation rules and simple mathematical logic and using variable linguistics and membership functions on each parameter adjusted to 6,561 rule base, so that the province of Java was chosen The West is worthy of hosting the next NSW.

We were aware of the many deficiencies that exist in the research we wrote. Therefore, we hope that this research can be developed with other authors or teams. Our hope as writers is that this study can be utilized by the NSW organizer, namely INSC. We also hope that this research can help the researchers or other research teams in completing the same research.

\section{ACKNOWLEDGEMENT}

We thank Bina Nusantara University for providing sponsorship support in this research. We also thank the lecturer who gave us the opportunity and direction to complete this research in order to complete the study of Bina Nusantara Graduate Program, Master of Computer Science. Hopefully this research can be utilized and useful for many people.

\section{REFERENCES}

1. D. N. Utama. Sistem Penunjang Keputusan: Filosofi, Teori, dan Implementasi. Yogyakarta: Penerbit Garudhawaca, 2017.

2. A. Kadir. Pengenalan Sistem Informasi Edisi Revisi. Yogyakarta: Penerbit ANDI Yogyakarta, 2014.

3. L. A. Zadeh. Fuzzy sets as a basis for a theory of possibility. Div. Comput. Sci. Sci. Comput, Vol. 1, pp. 3-28, 1978.

4. S. J. Pasaribu. Implementasi sistem pendukung keputusan menggunakan logika fuzzy untuk penerimaan beasiswa di politeknik piksi ganesha bandung. Seminar Nasional Teknologi Informasi dan Komunikasi, pp. 80-89, 2016.

5. D. N. Utama and U. Taryana. Fuzzy logic for simply prioritizing information in academic information system. International Journal of Mechanical Engineering and Technology, Vol. 10, No. 2, pp. 1594-1602, 2019.

6. R. Safitri and Erman. Pengelolaan venue pekan olahraga nasional (pon) XVIII provinsi Riau tahun 2012 dilihat dari perspektif desentralisasi. Jurnal Online Mahasiswa (JOM) Bidang Ilmu Sosial dan Ilmu Politik, Vol. 1, No. 1, 2014.

7. G. Brown. Emerging issues in olympic sponsorship: implications for host cities. Sport Management Review, Vol. 3, No. 1, pp. 71-92, 2000.
8. C. Persson. The olympic games site decision. Tourism Management, Vol. 23, No. 1, pp. 27-36, 2002. https://doi.org/10.1016/S0261-5177(01)00060-7

9. N. Rokhim. Studi Keadaan Sarana dan Prasarana Olahraga Menjelang Pekan Olahraga Provinsi XIII Tahun 2009 di Solo. Thesis, Fakultas Keguruan dan Ilmu Pendidikan, Universitas Sebelas Maret, 2010.

10. C. W. Johnson. Using evacuation simulations for contingency planning to enhance the security and safety of the 2012 olympic venues. Safety Science, Vol. 46, No. 2, pp. 302-322, 2008.

11. Z. Tan, J. Li, and G. Hu. (2014). Risk assessment and countermeasures of gas accidents in the sensitive areas under control during the Olympic Games in Beijing. Safety Science, Vol. 62, pp. 187-204, 2014. https://doi.org/10.1016/j.ssci.2013.08.008

12. B. M. Mills and M. S. Rosentraub. Hosting mega-events: A guide to the evaluation of development effects in integrated metropolitan regions. Tourism Management, Vol 34, pp. 238-246, 2013.

13. D. N. Utama and Rustamaji. Fuzzy decision support model for human resources performance appraisal. International Conference on Information Management and Technology, pp. 272-276, 2018.

14. D. N. Utama, S. Arrahmani, I. Wirahmadayanti, and A. Ayuningtias. Decision support model based on fuzzy-logic conception in determining region - "ojek online" trasnporter approriateness. International Journal of Emerging Trends in Engineerig Research, Vol. 8, No. 5, pp. 1523-1528, 2020. https://doi.org/10.30534/ijeter/2020/08852020

15. D. N. Utama, H. Risnanto, R. Putra, T. N. H. Hersyaf, and R. H. Oktalasa. Fuzzy decision support model for determining plants planted in specific suitable areas in Indonesia. International Journal of Emerging Trends in Engineerig Research, Vol. 8, No. 5, pp. 1517-1522, 2020.

https://doi.org/10.30534/ijeter/2020/07852020 